\title{
Motivations for new psychoactive substance use among regular psychostimulant users in Australia
}

Sutherland, Rachel; Bruno, Raimondo; Peacock, Amy; Lenton, Simon; Matthews, Allison; Salom, Caroline; Dietze, Paul

https://researchrepository.rmit.edu.au/esploro/outputs/9921861296401341/filesAndLinks?institution=61RMIT_INST\&index=null

Sutherland, R., Bruno, R., Peacock, A., Lenton, S., Matthews, A., Salom, C., Dietze, P., Butler, K., Burns, L., \& Barratt, M. (2017). Motivations for new psychoactive substance use among regular psychostimulant users in Australia. International Journal of Drug Policy, 43, 23-32. https://doi.org/10.1016/j.drugpo.2016.12.021 Document Version: Accepted Manuscript

Published Version: https://doi.org/10.1016/j.drugpo.2016.12.021

Repository homepage: https://researchrepository.rmit.edu.au CC BY-NC-ND V4.0

(C) 2017 Elsevier B.V. All rights reserved.

Downloaded On 2023/04/26 16:19:16 +1000 
Motivations for New Psychoactive Substance Use among Regular Psychostimulant Users in Australia

Rachel Sutherland ${ }^{*}{ }_{1}$, Raimondo Bruno ${ }^{1,2}$, Amy Peacock $^{2}$, Simon Lenton ${ }^{3}$, Allison Matthews ${ }^{2}$, Caroline Salom ${ }^{4}$, Paul Dietze ${ }^{5}$, Kerryn Butler ${ }^{1}$, Lucinda Burns ${ }^{1}$, Monica J. Barratt ${ }^{1,3,5}$

${ }^{1}$ National Drug and Alcohol Research Centre, University of New South Wales, Sydney, NSW, Australia

${ }^{2}$ School of Medicine (Psychology), Faculty of Health, University of Tasmania, Hobart, TAS, Australia

${ }^{3}$ National Drug Research Institute, Curtin University, Shenton Park, WA, Australia

${ }^{4}$ School of Public Health, Faculty of Medicine, University of Queensland, Brisbane, QLD, Australia

${ }^{5}$ Burnet Institute, Centre for Population Health, Melbourne, Victoria, Australia

Journal: International Journal of Drug Policy

Number of manuscript pages: 13

Number of tables: 2 (9 in appendix)

Number of figures: 0

Corresponding Author*: Rachel Sutherland

National Drug and Alcohol Research Centre, University of New South Wales, Sydney, NSW, 2052, AUSTRALIA; Phone: +61 29385 0256; Facsimile: +61 (0)2 9385 0222; E-mail:

rachels@unsw.edu.au 


\section{Abstract}

Objective: Examine the motivations for new psychoactive substance (NPS) use amongst a sample of regular psychostimulant users (RPU) in Australia, and determine whether motivations differ across substances.

Method: Data were obtained from 419 RPU interviewed for the 2014 Ecstasy and related Drugs Reporting System who reported lifetime NPS use. Based on the most recent NPS used, motivations for use were rated on an 11-point scale ( 0 'no influence' to 10 'maximum influence').

Results: For NPS overall, value for money was found to be the most highly endorsed motivation for use, scoring a median of five out of ten. However, there was substantial variation in motivations for use across substance types. Availability (i.e. no other drug was available to me at the time; $6 / 10$ ) was the most highly endorsed motivation for the use of synthetic cathinones, which was significantly higher than reported for DMT. Perceived legality and availability were the most highly endorsed motivations for synthetic cannabinoids (5/10); perceived legality scored higher for synthetic cannabinoids than for all the other NPS, whilst in regards to availability synthetic cannabinoids scored significantly higher than DMT only. Value for money was the most highly endorsed motivation for NBOMe (8/10) and 2C-family substances (5/10); in regards to NBOMe this scored significantly higher than all other NPS. Short effect duration was the most highly endorsed motivation for DMT (7/10), which was significantly higher than for all other NPS.

Conclusion: Synthetic cathinones and cannabinoids appear to be largely motivated by 'opportunistic' reasons (i.e. availability, legality), while NBOMe, 2C-family substances and DMT appear to be motivated by particular desirable qualities of a substance (i.e. value for money, short effect duration). Providing a nuanced understanding of why individuals use particular NPS improves our ability to understand the NPS phenomenon and to tailor harm reduction messages to the appropriate target groups. 
Keywords: New psychoactive substances; synthetic cannabinoids; synthetic cathinones; $2 \mathrm{C}-\mathrm{x}$; NBOMe; DMT; motivations 


\section{Introduction}

The European Monitoring Centre for Drugs and Drug Addiction (EMCDDA) has defined new psychoactive substances (NPS) as substances that are "not controlled by the 1961 Convention on Narcotic Drugs or the 1971 Convention on Psychotropic Substances, but which may pose a public health threat" (European Monitoring Centre for Drugs and Drug Addiction, 2016b, p.6). However, there is no universally accepted definition of NPS, and definitions vary across countries and jurisdictions. Indeed, it could be argued that the importance of 'older-new' drugs, such as those controlled by international legislation but not previously well-established in the recreational drugusing scene (e.g. dimethyltryptamine; DMT), must not be overlooked. In 2015 the European Union were monitoring over 560 different NPS, of which $70 \%$ were detected in the past five years (European Monitoring Centre for Drugs and Drug Addiction, 2016b). The rapid growth of the NPS market has been facilitated by a number of factors, including: the MDMA (ecstasy) shortage that occurred in the mid-2000s (resulting in pills with a low MDMA content, which often contained other drugs such as mephedrone, benzylpiperazine (BZP) and meta-chlorophenylpiperazine (mCPP); Brunt, Poortman, Niesink, \& van den Brink, 2011; United Nations Office on Drugs and Crime, 2014; Vogels et al., 2009); improving technological capabilities in China and India; increased communication and trade via the internet; and the ability to produce new substances in small laboratories (European Monitoring Centre for Drugs and Drug Addiction, 2016a; Reuter \& Pardo, 2017).

In addition to understanding the broader global factors that facilitated the growth of the NPS market, it is also important to examine individual motivations for NPS use. Understanding what is driving market changes can inform evaluation of policy changes (Reuter \& Pardo, 2017) and the development of effective harm reduction campaigns, and it may also provide some insight into which NPS are likely to become established in the recreational drug scene. For example, motivations such as legality and availability suggest more opportunistic reasons for use which may not be stable over the long-term (e.g. many countries have since moved to prohibit NPS). However, motivations 
based on preference or perceived 'superiority' over other drugs, may suggest sustained popularity for a given drug over the long-term.

It has been argued that NPS appeal to three distinct groups of people: those attracted to the legality (or perceived legality) of these substances, those looking to avoid detection in drug tests, and those seeking a new and attractive experience (Reuter \& Pardo, 2017). This view is partly supported by previous research. Legal status was initially considered to be an important contributor to the uptake of NPS. In the UK it was found that once mephedrone was listed as a controlled substance, selfreported use fell (Lader, 2015); similarly, following the prohibition of BZP in New Zealand, there was a decline in self-reported use among the general population (Wilkins \& Sweetsur, 2013). However, it is unclear if such declines were the result of reduced availability following the legislative changes or if they were the result of a general deterrent effect (or both). Indeed, a number of NPS have remained relatively common despite their subsequent prohibition, and in such cases legal status is considered to be a secondary driver for use, particularly among those who already use illicit drugs (Measham \& Newcombe, 2016). In addition, whilst some studies have identified the avoidance of drug use detection as a motivating factor for NPS use (Barratt, Cakic, \& Lenton, 2013; Bonar, Ashrafioun, \& Ilgen, 2014; Gunderson, Haughey, Ait-Daoud, Joshi, \& Hart, 2014), it has generally been found that, overall, this is less important than intrinsic motivations such as pleasure and thrill seeking (Barratt, Allen, \& Lenton, 2014; Orsolini, Papanti, Francesconi, \& Schifano, 2015; Soussan \& Kjellgren, 2015, 2016), and curiosity (Barratt et al., 2013; Bonar et al., 2014; Cakic, Potkonyak, \& Marshall, 2010). This finding may be because, to-date, only a relatively small proportion of the population is subjected to workplace or other (e.g. sporting or criminal justice) drug testing. The groupings put forward by Reuter and Pardo (2017) also fail to account for people who are attracted to NPS for reasons such as price, purity, availability and perceived safety (Barnard, Russell, McKeganey, \& Hamilton-Barclay, 2016; Barratt et al., 2013; Bonar et al., 2014; Lawn, Barratt, Williams, Horne, \& Winstock, 2014; Soussan \& Kjellgren, 2015, 2016; van Amsterdam, Nabben, Keiman, Haanschoten, \& Korf, 2015; Winstock, Lawn, Deluca, \& Borschmann, 2016). 
Given the array of NPS available, it is likely that motivations for use vary across substances. Although a number of studies have examined the motivations for use of a specific NPS, to the best of our knowledge, there is only one existing published study which has explicitly compared motivations across NPS. Soussan and Kjellgren (2016) conducted an online survey of 619 international NPS users and their findings support the hypothesis that there are likely to be distinct motivation profiles across different substances. Although 'pleasure and enjoyment' was a common motivation across all NPS groups, the use of hallucinogens and dissociatives was substantially more motivated by exploration and spiritual attainment, whilst stimulants were typically used to enhance mental and physical abilities. In contrast, the use of synthetic cannabinoids was more motivated by circumstances such as price, legal status, availability and non-detectability on screening tests (Soussan \& Kjellgren, 2016).

Soussan and Kjellgren (2016) examined eight different motives, most of which were intrinsic in nature (e.g. pleasure and enjoyment; self-exploration or spiritual attainment) or related to the 'rewards' associated with use (e.g. enhanced mental or physical abilities; self-assertion or selfconfidence); only one motive was related to external factors (i.e. 'circumstances such as price, legal status, availability or non-detectability in screening tests'). We would argue that a stronger focus on external factors is important for two reasons. Firstly, most NPS users also use traditional illicit drugs (Australian Institute of Health \& Welfare, 2014; Palamar, 2015; Palamar \& Acosta, 2015) and many of the motivations for use of these substances are likely to overlap (e.g. the intrinsic motivations for using hallucinogenic NPS are likely the same for using 'traditional' hallucinogenic substances); as such it is more meaningful to determine what factors motivate one to use NPS over traditional illicit drugs. Secondly, external motivations are more amenable to change though policy and treatment.

As such, the objective of the current paper was to add to the work by Soussan and Kjellgren (2016) by giving greater emphasis to external motivations (and examining price, legal status and drug testing separately). Specifically, we aimed to: 
1) Explore the motivations for using 'any' NPS among a sample of regular psychostimulant users (RPU) in Australia.

2) Determine whether there are differing motivations for use across the following NPS: synthetic cathinones, 2C-x, NBOMe, DMT and synthetic cannabinoids.

\section{Method}

\subsection{Study design}

This paper uses data from the 2014 Ecstasy and related Drugs Reporting System (EDRS) (for full study details, see Sindicich \& Burns, 2015). The EDRS is a national monitoring study aimed at detecting emerging trends in illicit drug markets and has been conducted annually within all Australian capital cities since 2003. The EDRS has received ethical approval from the University of New South Wales (UNSW) Human Research Ethics Committee (HC10071, HC15015), as well as from the relevant ethics committees in other Australian jurisdictions.

\subsection{Participants and procedure}

EDRS participants (hereafter referred to as 'regular psychostimulant users' (RPU)) comprised a nonrandom self-selected sample recruited through street-press advertisements, online forums and peer referral. Eligibility criteria were: at least monthly use of ecstasy or other psychostimulants in the preceding six months, 16 years of age or older, and residence in the city of interview for at least 12 months prior to the interview. Face-to-face one-hour structured interviews were conducted by trained interviewers at a negotiated time and location, and participants were reimbursed AUD40.

\subsection{Measures relevant to the current study}

In addition to demographic questions (i.e., age, gender, sexual orientation, employment and educational status), participants were asked about their lifetime and past six-month use of licit and 
illicit substances. They were also asked about their lifetime and past six-month use of 26 specific NPS (see Table 1 for a full list); an open text 'other' option was provided to capture additional NPS not listed in the survey. For each NPS used in the past six months, participants were asked whether they had been offered it or specifically sought it out. Participants who reported lifetime use of NPS were asked, based on the NPS that they had used most recently, to rate on a scale of 0-10 (0 'no influence' to 10 'maximum influence') how much each of the following factors motivated them to use this substance: legality (i.e. they thought it was legal to purchase/consume); easy to buy on the internet; convenient to have it posted to them after purchasing on the internet; high level of purity compared to 'traditional' illicit substances; good value for money; better high than 'traditional' illicit substances; fewer side effects than 'traditional' illicit substances; short-lasting effects; unable to be detected by drug testing; safer than 'traditional' illicit substances; and availability (i.e. no other drug available to them at the time).

\subsection{Statistical analysis}

Motivations were compared between the most commonly used NPS, namely synthetic cathinones (i.e. mephedrone and methylone; $n=53)$, the 2 C-family substances $(2 C-x ; n=101)$, NBOMe $(n=49)$, DMT $(n=92)$ and synthetic cannabinoids $(n=40)$. Since some of the variables were skewed (i.e. skewness $> \pm 1$ or kurtosis $> \pm 3$ ) non-parametric tests were conducted; Mood's median test was used due to the violation of the homogeneity of variance. For those motivations where significant differences were found between drugs $(p<0.05)$, pairwise post-hoc analyses were conducted to determine where the differences lay. A Bonferroni correction was applied in order to control for multiple comparisons, resulting in an adjusted $p$-value of $\leq 0.005$. To facilitate interpretation (given the large number of medians and interquartile ranges (IQR) which equal zero), the percentage who nominated scores of five or more out of ten (indicating strong endorsement) are also reported (Table 2). All analyses were conducted using IBM SPSS Statistics for Windows release 22.0 (IBM Corporation, 2013). 


\section{Results}

\subsection{Sample characteristics}

In 2014, 800 participants were recruited and interviewed for the EDRS. Analysis is based on a subset of participants who reported lifetime use of NPS and who were willing to answer questions about their motivations for use $(n=419)$. Of this sub-sample, seventy-three percent of participants were male with a median age of 21 years (IQR 19-24), 96\% were of English speaking background, 44\% were tertiary qualified, $68 \%$ were employed in some capacity, $39 \%$ were students, $14 \%$ were unemployed and $2 \%$ were currently in drug treatment. The majority $(99 \%)$ of participants reported recent (past six month) use of ecstasy, $51 \%$ reported recent methamphetamine use, $47 \%$ reported recent cocaine use, $53 \%$ reported recent LSD use and $88 \%$ reported recent cannabis use. Thirty-nine percent of participants reported using ecstasy or related drugs on a weekly or greater basis in the past month.

\subsection{Rates of use}

Seventy percent of the entire sample reported that they had used 'any' NPS in their lifetime and 41\% reported use in the six months preceding interview. The most commonly used NPS within the preceding six months were DMT (14\%), 2C-B (12\%), NBOMe (9\%) and mephedrone (5\%), although frequency of use for each of these drugs was low (range: 1-2 days). Approximately half of recent DMT (49\%), 2C-B (50\%) and NBOMe (54\%) users reported that they had sought out these substances, compared to only one-third (34\%) of recent mephedrone users (Table 1 ).

\section{Table 1}

\subsection{Motivations}

When considering NPS overall, none of the motivations asked about were rated particularly highly. Value for money was the most highly endorsed motivation for use of any NPS, scoring a median of 
five out of ten, and with $59 \%$ of users nominating a score of five or more. This was followed by ' thought it would give a better high' (3/10; 44\% nominating a score of $\geq 5$ ) and 'I thought it would have a high level of purity' $(2 / 10 ; 41 \%$ nominating a score of $\geq 5)$ (Table 2$)$. There was significant variation in most of the motivations for use when compared between drug types (see Table 2). However, there were no significant differences between drug types for 'I thought it would give a better high' or 'I thought it would have a high level of purity', and hence no post-hoc analyses were conducted for these motivations.

\section{Table 2}

\subsubsection{Synthetic cathinones}

The most highly endorsed motivation for the use of synthetic cathinones was availability (i.e. no other drug was available to me at the time; median $6 / 10 ; 57 \%$ nominating a score of $\geq 5$ ); however, this only differed significantly from DMT, which scored a median of $0 / 10$. The second most endorsed motivation for the use of synthetic cathinones was value for money $(5 / 10 ; 60 \%$ nominating a score of $\geq 5)$, although this was significantly lower than for NBOMe $(8 / 10)$ and not statistically different from scores for the other NPS.

\subsection{2 $2 C-x$}

The most highly endorsed motivation for the use of $2 \mathrm{C}-\mathrm{x}$ was value for money $(5 / 10 ; 65 \%$ nominating a score of $\geq 5$ ); this score was significantly lower than for NBOMe which scored a median of $8 / 10$ and significantly higher than synthetic cannabinoids which scored a median of $3 / 10$. The second most endorsed motivation for the use of $2 \mathrm{C}-\mathrm{x}$ was the perception of a better high $(4 / 10 ; 47 \%$ nominating a score of $\geq 5$ ), although this did not differ significantly from any of the other NPS.

\subsubsection{DMT}


The most highly endorsed motivation for the use of DMT was short effect duration $(7 / 10 ; 69 \%$ nominating a score of $\geq 5$ ); this score was significantly higher than for all the other NPS. The second most endorsed motivation was the perception of a better high $(5 / 10 ; 55 \%$ nominating a score of $\geq 5)$, although this did not differ significantly from any of the other NPS.

\subsubsection{NBOMe}

The most highly endorsed motivation for the use of NBOMe was value for money $(8 / 10 ; 80 \%$ nominating a score of $\geq 5$ ); this score was significantly higher than for all the other NPS. The second most endorsed motivation was a higher level of purity $(5 / 10 ; 54 \%$ nominating a score of $\geq 5)$, although this rating did not differ significantly from any of the other NPS. The ability to easily purchase NBOMe on the internet scored a median rating of 0.5 ( $38 \%$ nominating a score of $\geq 5)$; although this is a low rating, it was significantly higher than scored by all the other NPS.

\subsubsection{Synthetic cannabinoids}

The most highly endorsed motivations for the use of synthetic cannabinoids were legality $(5 / 10 ; 54 \%$ nominating a score of $\geq 5)$ and availability $(5 / 10 ; 56 \%$ nominating a score of $\geq 5)$. The rating of legality was significantly higher for synthetic cannabinoids than all other NPS, whilst in regards to availability synthetic cannabinoids scored significantly higher than DMT only.

\section{Discussion}

We found significant variation in the motivations for using NPS. When examined as a homogenous group of drugs, it was found that the most highly endorsed motivation for using 'any' NPS was value for money. However, when synthetic cathinones, 2C-x, NBOMe, DMT and synthetic cannabinoids were examined individually, we found substantial differences in the primary motivations for use. These results are similar to Soussan and Kjellgren's (2016) finding of distinct motivation profiles across NPS, and builds upon their work by giving more focus to external factors. 
The most highly endorsed motivation for synthetic cathinone use was availability (i.e. no other drug available to me at the time), potentially indicative of more opportunistic use. Further, two-thirds of those who had recently used mephedrone (the most commonly used cathinone among this sample), reported that the drug had been offered to them rather than sought out. These findings are consistent with previous work showing less favourable ratings in terms of pleasurable effects and likelihood of future use for synthetic cathinones (i.e. mephedrone, methylone, methylenedioxypyrovalerone) compared to ecstasy and cocaine (Matthews et al., In Press).This suggests that synthetic cathinone use may be less likely to persist within Australia's recreational drug scene unless there are also changes to external drivers such as the price and availability of traditional substances. Interestingly, a previous study of RPU in Australia found that although synthetic cathinones were the most commonly used NPS in 2010, by 2015 there had been a significant decline in their use (Sutherland et al., 2016); this decline was likely due to number of factors including legislative change, consumer acceptability and external market factors such as availability.

The most highly endorsed reasons for synthetic cannabinoid use were legality (or perceived legality, since many synthetic cannabinoids are now prohibited across Australia e.g. Bright, Bishop, Kane, Marsh, \& Barratt, 2013), and availability. Legality as a motive scored higher for synthetic cannabinoids than for all the other NPS, whilst in regards to availability synthetic cannabinoids scored significantly higher than DMT only. The majority of synthetic cannabinoid users reported that these substances had been offered to them, rather than specifically sought out, again indicating more opportunistic use. Combined, these findings suggest that while legality and availability may have encouraged initiation of synthetic cannabinoid use, continued uptake will likely be limited among established illicit drug users - particularly since they generally have ready access to traditional cannabis. Indeed, participants in this sample largely report that both outdoor-cultivated ('bush') and indoor-cultivated hydroponic cannabis are 'easy' or 'very easy' to obtain (79\% and 92\% respectively) and this has remained consistent over time (Sindicich \& Burns, 2015). This hypothesis is 
supported by studies showing significant declines in self-reported use of synthetic cannabinoids over time (Johnston, O'Malley, Bachman, Schulenberg, \& Miech, 2015; Sutherland et al., 2016), as well as by studies documenting the negative effect profile of synthetic cannabinoids (Barratt et al., 2013; Winstock \& Barratt, 2013).

Value for money was the most highly endorsed motivation for both NBOMe and $2 \mathrm{C}-\mathrm{x}$. This motivation was particularly prominent for NBOMe, with a significantly higher score relative to all other NPS. This is perhaps not surprising given that LSD blotters are reported to be 5-10 times more expensive than NBOMe blotters sold via online marketplaces (Erowid, 2013). The perception of a better high and a higher level of purity than traditional illicit drugs were the second most endorsed motivations for $2 \mathrm{C}-\mathrm{x}$ and NBOMe, respectively (although median ratings for these motivations did not differ significantly relative to other NPS). These motivating factors are supported by studies which have shown that both NBOMe and $2 \mathrm{CB}$ are perceived favourably in terms of strength of effect and pleasurability - although it is important to note that LSD was rated more favourably than $2 \mathrm{CB}$ in terms of pleasurable effects and likelihood of using again (Lawn et al., 2014; Matthews et al., In Press). In addition, about half of recent NBOMe and 2C-x users reported that they had specifically sought out these substances. Combined, these factors suggest potential long-term, sustained popularity of both $2 \mathrm{C}-\mathrm{x}$ and NBOMe. Indeed, rates of past six month phenethylamine NPS use (including NBOMe and 2C-x) among RPU were found to have increased significantly over time, from $8.0 \%$ in 2010 to $18.6 \%$ in 2015 (Sutherland et al., 2016).

The most highly endorsed motivation for DMT use was the short duration of its effects. When smoked, DMT generally reaches full effects within 10-60 seconds of inhalation and lasts approximately 5-20 minutes (Erowid, 2015). This is in stark contrast to traditional psychedelic substances (e.g. duration of LSD is 6-11 hours, magic mushrooms 4-7 hours; Erowid, 2016a, 2016b); high endorsement suggests that this is a desirable quality among this sample of RPU. Previous studies have shown that, when compared to other hallucinogens, DMT was rated favourably in terms of strength of effect and pleasure (Matthews et al., In Press; Winstock, Kaar, \& Borschmann, 
2014). Indeed, rates of tryptamine use (primarily DMT) among RPU increased significantly from 2010-2015 (Sutherland et al., 2016); DMT appears to have become well-established within Australia's recreational drug scene and its popularity seems unlikely to diminish within the foreseeable future.

\subsection{Strengths, Limitations and Future Research}

This study provides a unique insight into patterns and drivers of NPS use amongst RPU in Australia, however certain aspects of the design should be considered when interpreting the findings. The study uses a sentinel, non-representative, sample to identify trends in illicit drug markets, which is particularly important when monitoring marketplaces which are rapidly changing (as is the case for NPS). Whilst participants are recruited from all capital cities in Australia, the present findings may not be generalisable to all RPU in Australia, nor are they generalisable to all NPS users in Australia. For example, legality and availability may be more important motivating factors for 'novice' drug users and those without established contact with illicit subcultures and illegal economies. Similarly, the avoidance of drug use detection may be more important for individuals who are subjected to regular drug testing (e.g. prisoners and people in certain professions; Measham \& Newcombe, 2016). Nevertheless, given the unique motivation profiles found in both our and Soussan and Kjellgren's (2016) studies, it would be of benefit to develop a standardised motivation scale specific to NPS, with demonstrated validity and reliability. This would facilitate comparisons between studies, over time and across countries; this is particularly important given that differences in local drug markets, as well as differences in legal and social contexts, will likely result in country specific variations in the motivations for NPS use.

In regards to individual differences driving motivations, it is important to note that the current analyses were between-subject, where participants were grouped into NPS classes based only on the most recent substance used (i.e. not the potential full array of NPS used), and systematic differences between NPS consumer types may partly explain different motivational profiles for NPS. These 
factors could be explored further in future work via analyses which take into account heterogeneity in NPS consumer samples; within-subject research with polydrug NPS consumers which compares motivations for different NPS use by the same individual; and longitudinal studies which track trajectories of NPS use over time for the same individual.

Finally, our analysis is reliant upon self-report data from participants which may be subject to bias, although evidence points to sufficient validity and reliability of self-report in studies assessing illicit drug use (Darke, 1998). Our findings are also based on relatively small sample sizes and as such caution must be exercised when interpreting null results.

\subsection{Conclusion}

In summary, we found significant variation in the motivations for using different NPS. Our sample of RPU were a diverse community of drug users who had used NPS for a variety of reasons. Providing a nuanced understanding of why individuals use particular NPS improves our ability to understand the NPS phenomenon and to tailor harm reduction messages to the appropriate target groups. For example, participants who use NPS for opportunistic reasons (e.g. synthetic cannabinoids because they thought it was legal, or because no other drug was available to them) might be more receptive to an education-based campaign surrounding the legal status and harms associated with these substances. However, participants who use NPS because they are perceived as a superior product, or to have desirable qualities, are less likely to cease use of these substances and may benefit more from policy responses like chill-out rooms in nightlife settings and on-site chemical analyses of drug samples (refer to European Monitoring Centre for Drugs and Drug Addiction, 2016b for a broad coverage of potential NPS interventions).

Furthermore, we found that the varying motivations appeared to correspond with trends in use over time. That is, NPS which were used for 'opportunistic' reasons (e.g. availability, legality) were found to have declined in use over time, while NPS use motivated by the desirable qualities of a substance (e.g. value for money, short effect duration) or the perception of a superior product (e.g. better 
high/purity) corresponded with increases in use over time. Our findings, combined with previous studies showing the positive and negative effect profiles of various NPS, suggest that NBOMe, $2 \mathrm{C}-\mathrm{x}$ and DMT may maintain popularity within Australia's recreational drug scene (although it is important to note that frequency of use remains extremely low: 1-2 days in past six months). In contrast, sustained use of synthetic cathinones and cannabinoids seems unlikely, unless there are also changes to external drivers such as the price and availability of traditional substances. Indeed, although the majority $(70 \%)$ of NPS being monitored by the EMCDDA fall into the stimulant and synthetic cannabinoid effect classes (European Monitoring Centre for Drugs and Drug Addiction, 2016b), psychedelic NPS (i.e. DMT, NBOMe and 2C-x) remain the most commonly sold NPS on dark net marketplaces (Van Buskirk, Roxburgh, Bruno, \& Burns, 2015). Furthermore, a recent study of experienced recreational drug users found that while participants were more likely to have ever used stimulant NPS, in the future they predominantly intended to try psychedelic NPS (van Amsterdam et al., 2015). This is not to say that these substances will replace traditional illicit drugs, but rather will likely complement them (Moore, Dargan, Wood, \& Measham, 2013). Of course, given the rapidly evolving nature of the NPS marketplace it is impossible to predict its future with any certainty; in many respects, these trends will vary according to the availability of better established substances, as well as the nature of newly emergent products. In the meantime, we must remain vigilant and increase our capacity to detect and respond to new trends in a timely manner. 


\begin{tabular}{|c|c|c|c|c|c|}
\hline & $\begin{array}{l}\text { Lifetime use } \\
\quad \%(n)\end{array}$ & $\begin{array}{c}\text { Recent use } \\
\% \text { (n) }\end{array}$ & $\begin{array}{l}\text { Median } \\
\text { days*\# } \\
\text { (range) }\end{array}$ & Offered*\# \% & Sought*\# \% \\
\hline \multicolumn{6}{|l|}{ Synthetic cathinones } \\
\hline Mephedrone (miaow, 4MMC) & $16.5(132)$ & 4.9 (39) & $2(1-60)$ & 65.8 & 34.2 \\
\hline Methylone (bk-MDMA) & $9.4(75)$ & $3.0(24)$ & $2(1-48)$ & 58.3 & 41.7 \\
\hline MDPV/Ivory wave & $2.9(23)$ & $0.8(6)$ & - & - & - \\
\hline Other synthetic cathinone & $1.1(9)$ & $0.3(2)$ & - & - & - \\
\hline Any synthetic cathinone ${ }^{\wedge}$ & $22.1(177)$ & $8.0(64)$ & $\mathrm{n} / \mathrm{a}$ & $\mathrm{n} / \mathrm{a}$ & $\mathrm{n} / \mathrm{a}$ \\
\hline DMT & $27.4(219)$ & $14.0(112)$ & $1(1-24)$ & 51.5 & 48.5 \\
\hline 5-MeO-DMT & $2.1(17)$ & $0.8(6)$ & - & - & - \\
\hline MDAI & $1.6(13)$ & $0.5(4)$ & - & - & - \\
\hline Benzo Fury & $1.3(10)$ & $0.4(3)$ & - & - & - \\
\hline BZP & $3.0(24)$ & $0.3(2)$ & - & - & - \\
\hline 5-IAI & $0.4(3)$ & 0 & - & - & - \\
\hline PMA & $4.4(35)$ & $2.1(17)$ & $1(1-6)$ & 93.3 & 6.7 \\
\hline MXE & $4.3(34)$ & $1.6(13)$ & $4(1-15)$ & 69.2 & 30.8 \\
\hline LSA & $5.3(42)$ & $1.4(11)$ & $2(1-3)$ & 30 & 70 \\
\hline DOI & $1.5(12)$ & $0.1(1)$ & - & - & - \\
\hline \multicolumn{6}{|l|}{$2 C-x$} \\
\hline $2 C-B$ & $25.9(207)$ & $11.5(92)$ & $1.5(1-24)$ & 50.0 & 50.0 \\
\hline $2 C-1$ & $15.8(126)$ & $5.6(45)$ & $1(1-24)$ & 57.1 & 42.9 \\
\hline $2 C-E$ & $5.9(47)$ & $0.9(7)$ & - & - & - \\
\hline 2C-other & $2.8(22)$ & $0.4(3)$ & - & - & - \\
\hline Any $2 C-x^{\wedge \wedge}$ & $33.0(264)$ & $14.5(116)$ & $\mathrm{n} / \mathrm{a}$ & $\mathrm{n} / \mathrm{a}$ & $\mathrm{n} / \mathrm{a}$ \\
\hline NBOMe & $12.8(102)$ & $9.0(72)$ & $2(1-48)$ & 45.7 & 54.3 \\
\hline \multicolumn{6}{|l|}{ Synthetic cannabis } \\
\hline K2/spice & $7.6(61)$ & $1.8(14)$ & $2.5(1-14)$ & 75 & 25 \\
\hline Kronic & $18.0(144)$ & $3.1(25)$ & $2.5(1-50)$ & 68 & 32 \\
\hline Other synthetic cannabinoid & $8.6(69)$ & $2.6(21)$ & $1(1-90)$ & 55 & 45 \\
\hline Any synthetic cannabinoid^^^^ & $28.5(228)$ & $6.9(55)$ & $\mathrm{n} / \mathrm{a}$ & $\mathrm{n} / \mathrm{a}$ & $\mathrm{n} / \mathrm{a}$ \\
\hline Mescaline & $8.1(65)$ & $1.9(15)$ & $1(1-3)$ & 83.3 & 16.7 \\
\hline Salvia divinorum & $10.5(84)$ & $1.8(14)$ & $1(1-12)$ & 58.3 & 41.7 \\
\hline Datura & $3.3(26)$ & $0.1(1)$ & - & - & - \\
\hline Herbal high & $17.5(140)$ & $4.3(34)$ & $1(1-30)$ & 33.3 & 66.7 \\
\hline
\end{tabular}

*Among those who had used in the past six months

"Data not presented where $\mathrm{n}<10$

${ }^{\wedge}$ Collapses figures for mephedrone, methylone, MDPV and other synthetic cathinone. This was done for lifetime and recent use only; since participants may have used more than one type of synthetic cathinone we were unable to collapse figures for the last three columns. $\wedge^{\wedge}$ Collapses figures for 2C-B, 2C-I. 2C-E and 2C-other. This was done for lifetime and recent use only; since participants may have used more than one type of $2 \mathrm{C}$ substance we were unable to collapse figures for the last three columns.

$\wedge \wedge \wedge$ Collapses figures for K2/spice, Kronic and other synthetic cannabinoids. This was done for lifetime and recent use only; since

participants may have used more than one type of synthetic cathinone we were unable to collapse figures for the last three columns. 


\begin{tabular}{|c|c|c|c|c|c|c|c|c|c|c|c|c|c|c|}
\hline & \multicolumn{2}{|c|}{$\begin{array}{c}\text { Any NPS } \\
\text { (combined) }^{\#} \\
n=419\end{array}$} & \multicolumn{2}{|c|}{$\begin{array}{c}\text { (a) Synthetic } \\
\text { cathinones } \\
n=53\end{array}$} & \multicolumn{2}{|c|}{$\begin{array}{l}\text { (b) } 2 C-x \\
n=101\end{array}$} & \multicolumn{2}{|c|}{$\begin{array}{c}\text { (c) DMT } \\
n=92\end{array}$} & \multicolumn{2}{|c|}{$\begin{array}{c}\text { (d) NBOMe } \\
n=49\end{array}$} & \multicolumn{2}{|c|}{$\begin{array}{c}\text { (e) Synthetic } \\
\text { cannabinoids } \\
n=40\end{array}$} & \multirow[t]{2}{*}{$\begin{array}{c}p ; \\
\text { Cramer's } \\
\text { V }\end{array}$} & \multirow[t]{2}{*}{$\begin{array}{l}\text { Post-hoc } \\
\text { analyses }^{\# \#}\end{array}$} \\
\hline & $\begin{array}{c}\% \\
\text { scored } \\
\geq 5^{*}\end{array}$ & $\begin{array}{c}\text { Median } \\
\text { score** } \\
\text { (IQR) }\end{array}$ & $\begin{array}{c}\% \\
\text { scored } \\
\geq 5^{*}\end{array}$ & $\begin{array}{c}\text { Median } \\
\text { score** } \\
\text { (IQR) }\end{array}$ & $\begin{array}{c}\% \\
\text { scored } \\
\geq 5^{*}\end{array}$ & $\begin{array}{c}\text { Median } \\
\text { score** } \\
\text { (IQR) }\end{array}$ & $\begin{array}{c}\% \\
\text { scored } \\
\geq 5^{*}\end{array}$ & $\begin{array}{c}\text { Median } \\
\text { score** } \\
\text { (IQR) }\end{array}$ & $\begin{array}{c}\% \\
\text { scored } \\
\geq 5^{*}\end{array}$ & $\begin{array}{c}\text { Median } \\
\text { score** } \\
\text { (IQR) }\end{array}$ & $\begin{array}{c}\% \\
\text { scored } \\
\geq 5^{*}\end{array}$ & $\begin{array}{c}\text { Median } \\
\text { score** } \\
\text { (IQR) }\end{array}$ & & \\
\hline Legal to buy & 17 & $0(0-0)$ & 8 & $0(0-0)$ & 4 & $0(0-0)$ & 2 & $0(0-0)$ & 17 & $0(0-0)$ & 54 & $5(0-10)$ & $\begin{array}{c}<0.001 ; \\
0.512\end{array}$ & $\begin{array}{c}e>a, b, c, d \\
d>c\end{array}$ \\
\hline $\begin{array}{l}\text { Easy to purchase } \\
\text { on internet }\end{array}$ & 15 & $0(0-0)$ & 10 & $0(0-0)$ & 11 & $0(0-0)$ & 14 & $0(0-0)$ & 38 & $\begin{array}{c}0.5(0- \\
7.75)\end{array}$ & 3 & $0(0-0)$ & $\begin{array}{c}<0.001 \\
0.337\end{array}$ & $d>a, b, c, e$ \\
\hline Postage & 13 & $0(0-0)$ & 10 & $0(0-0)$ & 10 & $0(0-0)$ & 12 & $0(0-0)$ & 35 & $\begin{array}{l}0(0- \\
7.75)\end{array}$ & 3 & $0(0-0)$ & $\begin{array}{c}<0.001 ; \\
0.294\end{array}$ & $d>a, b, c, e$ \\
\hline Higher purity & 41 & $2(0-7)$ & 35 & $0(0-6)$ & 38 & $2(0-6.5)$ & 41 & $2(0-7)$ & 54 & $\begin{array}{l}5(0- \\
8.75)\end{array}$ & 31 & $0(0-5)$ & $\begin{array}{l}0.139 \\
0.147\end{array}$ & - \\
\hline Value for money & 59 & $5(0-8)$ & 60 & $5(0-8)$ & 65 & $5(0-8)$ & 50 & $4.5(0-7)$ & 80 & $8(5-10)$ & 44 & $3(0-5)$ & $\begin{array}{c}<0.001 \\
0.286\end{array}$ & $\begin{array}{c}d>a, b, c, e ; \\
b>e\end{array}$ \\
\hline Better high & 44 & $3(0-7)$ & 29 & $0(0-5)$ & 47 & $4(0-7)$ & 55 & $5(0-8)$ & 43 & $4(0-6)$ & 33 & $2(0-5)$ & $\begin{array}{l}0.059 \\
0.168\end{array}$ & - \\
\hline $\begin{array}{l}\text { Fewer side } \\
\text { effects }\end{array}$ & 31 & $0(0-5)$ & 20 & $0(0-4)$ & 28 & $0(0-5)$ & 39 & $2(0-7)$ & 33 & $0(0-5.5)$ & 31 & $0(0-5)$ & $\begin{array}{c}0.017 \\
0.192\end{array}$ & - \\
\hline $\begin{array}{l}\text { Effect wouldn't } \\
\text { last too long }\end{array}$ & 36 & $0(0-6)$ & 20 & $\begin{array}{l}0(0- \\
2.25)\end{array}$ & 28 & $0(0-5)$ & 69 & $7(3-10)$ & 22 & $0(0-4)$ & 28 & $0(0-5)$ & $\begin{array}{c}<0.001 ; \\
0.414\end{array}$ & $c>a, b, d, e$ \\
\hline Drug testing & 18 & $0(0-1)$ & 2 & $0(0-0)$ & 13 & $0(0-0.5)$ & 18 & $0(0-1)$ & 25 & $0(0-5)$ & 28 & $0(0-5)$ & $\begin{array}{l}0.001 \\
0.240\end{array}$ & $a<b, c, d, e$ \\
\hline Safer & 26 & $0(0-5)$ & 12 & $0(0-0)$ & 19 & $0(0-3)$ & 37 & $0(0-5)$ & 31 & $0(0-5)$ & 39 & $0(0-5)$ & $\begin{array}{c}0.001 ; \\
0.238\end{array}$ & $a<c, d, e$ \\
\hline Availability & 32 & $0(0-7)$ & 57 & $6(0-10)$ & 31 & $0(0-6)$ & 11 & $0(0-0)$ & 20 & $0(0-3)$ & 56 & $5(0-10)$ & $\begin{array}{c}<0.001 ; \\
0.357\end{array}$ & $c<a, b, d, e$ \\
\hline
\end{tabular}

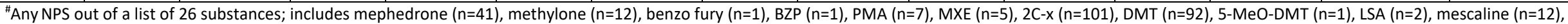
salvia divinorum ( $n=7)$, DXM ( $n=11)$, NBOMe ( $n=49)$, synthetic cannabis $(n=40)$, other $(n=37)$. "\#see appendix (Tables 3-11) for more detailed results. Post-hoc analyses only conducted for those motivations where significant differences were found; the last column shows where the significant differences lie. For example, e>a,b,c,d indicates that for the motivation 'legal to buy' synthetic cannabinoid users (e) nominated a significantly higher score than synthetic cathinone (a), 2C-x (b), DMT (c) and NBOMe (d) users. Note: $p \leq 0.005$ used in the post-hoc analyses to account for multiple comparisons; significant findings bolded. *Note: No analyses were conducted on these figures; they are presented to assist with ease of interpretation, given the large number of 0 (0-0) medians and interquartile ranges (IQR). **From 0 - 10 , with 0 being no influence and 10 being maximum influence. 


\section{APPENDIX}

Table 3: 'It was legal to buy': post-hoc comparisons across NPS, 2014

\begin{tabular}{|c|c|c|c|c|}
\hline & $\begin{array}{c}\text { 2C-x } \\
p ; \text { Cramer's V }\end{array}$ & $\begin{array}{c}\text { DMT } \\
p ; \text { Cramer's V }\end{array}$ & $\begin{array}{c}\text { NBOMe } \\
p ; \text { Cramer's V }\end{array}$ & $\begin{array}{c}\text { Synthetic } \\
\text { cannabinoids } \\
p ; \text { Cramer's V }\end{array}$ \\
\hline Synthetic cathinones & 0.495 & 0.237 & 0.098 & $\begin{array}{c}<0.001 \\
0.550\end{array}$ \\
\hline $2 C-x$ & & 0.560 & 0.007 & $\begin{array}{c}<0.001 \\
0.602\end{array}$ \\
\hline DMT & & & $\begin{array}{l}0.002 \\
0.269\end{array}$ & $\begin{array}{c}<0.001 \\
0.635\end{array}$ \\
\hline NBOMe & & & & $\begin{array}{c}<0.001 \\
0.405\end{array}$ \\
\hline Synthetic cannabis & & & & \\
\hline
\end{tabular}

Note: significance value of $p \leq 0.005$ was used to control for multiple comparisons; significant findings bolded. When significant differences were found, Cramer's V is also reported.

Table 4: 'It was easy to buy on the internet': post-hoc comparisons across NPS, 2014

\begin{tabular}{l|c|c|c|c}
\hline & $\mathbf{2 C - x}$ & DMT & NBOMe & $\begin{array}{c}\text { Synthetic } \\
\text { cannabinoids } \\
p ; \text { Cramer's V }\end{array}$ \\
\hline Synthetic cathinones & $p ;$ Cramer's V & $p ;$ Cramer's V & $p ;$ Cramer's V & $\begin{array}{c}<0.001 \\
0.387\end{array}$ \\
\hline 2C-x & 0.885 & 0.580 & $<0.001$ & 0.115 \\
\hline DMT & & 0.618 & $\mathbf{0 . 3 7 5}$ & 0.060 \\
\hline NBOMe & & & $<0.001$ & $<0.001$ \\
\hline Synthetic cannabinoids & & & $\mathbf{0 . 3 4 1}$ & $\mathbf{0 . 4 8 7}$ \\
\hline
\end{tabular}

Note: significance value of $p \leq 0.005$ was used to control for multiple comparisons; significant findings bolded. When significant differences were found, Cramer's V is also reported.

Table 5: 'It was convenient to have it posted to me after buying on the internet': post-hoc comparisons across NPS, 2014

\begin{tabular}{l|c|c|c|c}
\hline & 2C-x & DMT & NBOMe & $\begin{array}{c}\text { Synthetic } \\
\text { cannabinoids } \\
p ; \text { Cramer's V }\end{array}$ \\
\hline Synthetic cathinones & $p ;$ Cramer's V & $p ;$ Cramer's V & $p ;$ Cramer's V & 0.159 \\
\hline 2C-x & 0.902 & 0.853 & $\mathbf{0 . 0 0 1}$ & $\mathbf{0 . 3 2 5}$ \\
\hline DMT & & 0.938 & $<\mathbf{0 . 0 0 1}$ & 0.111 \\
\hline NBOMe & & & $\mathbf{0 . 3 1 5}$ & 0.103 \\
\hline
\end{tabular}




\section{Synthetic cannabinoids}

Note: significance value of $p \leq 0.005$ was used to control for multiple comparisons; significant findings bolded. When significant differences were found, Cramer's V is also reported.

Table 6: 'It was good value for money': post-hoc comparisons across NPS, 2014

\begin{tabular}{|c|c|c|c|c|}
\hline & $\begin{array}{c}\text { 2C-x } \\
p ; \text { Cramer's V }\end{array}$ & $\begin{array}{c}\text { DMT } \\
p ; \text { Cramer's V }\end{array}$ & $\begin{array}{c}\text { NBOMe } \\
p ; \text { Cramer's V }\end{array}$ & $\begin{array}{c}\text { Synthetic } \\
\text { cannabinoids } \\
p \text {; Cramer's V }\end{array}$ \\
\hline Synthetic cathinones & 0.582 & 0.357 & $\begin{array}{l}0.001 \\
0.326\end{array}$ & 0.018 \\
\hline $2 C-x$ & & 0.085 & $\begin{array}{c}<0.001 \\
0.307\end{array}$ & $\begin{array}{l}0.002 \\
0.262\end{array}$ \\
\hline DMT & & & $\begin{array}{c}<0.001 \\
0.336\end{array}$ & 0.505 \\
\hline NBOMe & & & & $\begin{array}{c}<0.001 \\
0.506\end{array}$ \\
\hline Synthetic cannabinoids & & & & \\
\hline
\end{tabular}

Note: significance value of $p \leq 0.005$ was used to control for multiple comparisons; significant findings bolded. When significant differences were found, Cramer's $V$ is also reported.

Table 7: 'Thought it would have fewer side effects than traditional illicit drugs': post-hoc comparisons across NPS, 2014

\begin{tabular}{l|c|c|c|c}
\hline & 2C-x & DMT & NBOMe & $\begin{array}{c}\text { Synthetic } \\
\text { cannabinoids } \\
p ; \text { Cramer's V }\end{array}$ \\
\hline Synthetic cathinones & $p ;$ Cramer's V & $p ;$ Cramer's V & $p ;$ Cramer's V & 0.453 \\
\hline $\mathbf{2 C - x}$ & 0.087 & 0.022 & 0.112 & 0.462 \\
\hline DMT & & 0.082 & 0.907 & 0.158 \\
\hline NBOMe & & & 0.334 & 0.457 \\
\hline Synthetic cannabinoids & & & & \\
\hline
\end{tabular}

Note: significance value of $p \leq 0.005$ was used to control for multiple comparisons; significant findings bolded. When significant differences were found, Cramer's V is also reported.

Table 8: 'I knew the effect wouldn't last too long': post-hoc comparisons across NPS, 2014

\begin{tabular}{|c|c|c|c|c|}
\hline & $\begin{array}{c}\mathbf{2 C - x} \\
p ; \text { Cramer's V }\end{array}$ & $\begin{array}{c}\text { DMT } \\
p ; \text { Cramer's V }\end{array}$ & $\begin{array}{c}\text { NBOMe } \\
p ; \text { Cramer's V }\end{array}$ & $\begin{array}{c}\text { Synthetic } \\
\text { cannabinoids } \\
p ; \text { Cramer's V }\end{array}$ \\
\hline Synthetic cathinones & 0.205 & $\begin{array}{c}<0.001 \\
0.377\end{array}$ & 0.122 & 0.197 \\
\hline $2 C-x$ & & $\begin{array}{c}<0.001 \\
0.413\end{array}$ & 0.616 & 0.789 \\
\hline DMT & & & $\begin{array}{c}<0.001 \\
0.456\end{array}$ & $\begin{array}{c}<0.001 \\
0.336\end{array}$ \\
\hline NBOMe & & & & 0.863 \\
\hline
\end{tabular}




\section{Synthetic cannabinoids}

Note: significance value of $p \leq 0.005$ was used to control for multiple comparisons; significant findings bolded. When significant differences were found, Cramer's V is also reported.

Table 9: 'I thought it couldn't be detected by drug testing': post-hoc comparisons across NPS, 2014

\begin{tabular}{|c|c|c|c|c|}
\hline & $\begin{array}{c}\text { 2C-x } \\
p ; \text { Cramer's V }\end{array}$ & $\begin{array}{c}\text { DMT } \\
p ; \text { Cramer's V }\end{array}$ & $\begin{array}{c}\text { NBOMe } \\
p ; \text { Cramer's V }\end{array}$ & $\begin{array}{c}\text { Synthetic } \\
\text { cannabinoids } \\
p ; \text { Cramer's V }\end{array}$ \\
\hline Synthetic cathinones & $\begin{array}{l}0.002 \\
0.260\end{array}$ & $\begin{array}{c}<0.001 \\
0.298 \\
\end{array}$ & $\begin{array}{c}<0.001 \\
0.428 \\
\end{array}$ & $\begin{array}{c}<0.001 \\
0.391 \\
\end{array}$ \\
\hline $2 C-x$ & & 0.572 & 0.079 & 0.309 \\
\hline DMT & & & 0.213 & 0.576 \\
\hline NBOMe & & & & 0.598 \\
\hline Synthetic cannabinoids & & & & \\
\hline
\end{tabular}

Note: significance value of $p \leq 0.005$ was used to control for multiple comparisons; significant findings bolded. When significant differences were found, Cramer's $V$ is also reported.

Table 10: 'I thought it would be safer than traditional illicit drugs': post-hoc comparisons across NPS, 2014

\begin{tabular}{l|c|c|c|c}
\hline & $\mathbf{2 C - x}$ & DMT & NBOMe & $\begin{array}{c}\text { Synthetic } \\
\text { cannabinoids } \\
p ; \text { Cramer's V }\end{array}$ \\
\hline Synthetic cathinones & $p$; Cramer's V & $p$; Cramer's V & $p$; Cramer's V & $\mathbf{0 . 0 0 2}$ \\
\hline $\mathbf{2 C - x}$ & 0.105 & $\mathbf{0 . 0 0 1}$ & $\mathbf{0 . 0 0 2}$ & $\mathbf{0 . 3 1 4}$ \\
\hline DMT & & 0.296 & 0.042 & 0.038 \\
\hline NBOMe & & & 0.983 & 0.869 \\
\hline Synthetic cannabinoids & & & & 0.868 \\
\hline
\end{tabular}

Note: significance value of $p \leq 0.005$ was used to control for multiple comparisons; significant findings bolded. When significant differences were found, Cramer's V is also reported.

Table 11: 'No other drug was available to me at the time': post-hoc comparisons across NPS, 2014

\begin{tabular}{|c|c|c|c|c|}
\hline & $\begin{array}{c}\text { 2C-x } \\
p ; \text { Cramer's V }\end{array}$ & $\begin{array}{c}\text { DMT } \\
p ; \text { Cramer's V }\end{array}$ & $\begin{array}{c}\text { NBOMe } \\
p ; \text { Cramer's V }\end{array}$ & $\begin{array}{c}\text { Synthetic } \\
\text { cannabinoids } \\
p ; \text { Cramer's V }\end{array}$ \\
\hline Synthetic cathinones & 0.050 & $\begin{array}{c}<0.001 \\
0.452\end{array}$ & 0.009 & 0.977 \\
\hline $2 C-x$ & & $\begin{array}{c}<0.001 \\
0.285\end{array}$ & 0.815 & 0.033 \\
\hline DMT & & & $<0.001$ & $<0.001$ \\
\hline
\end{tabular}




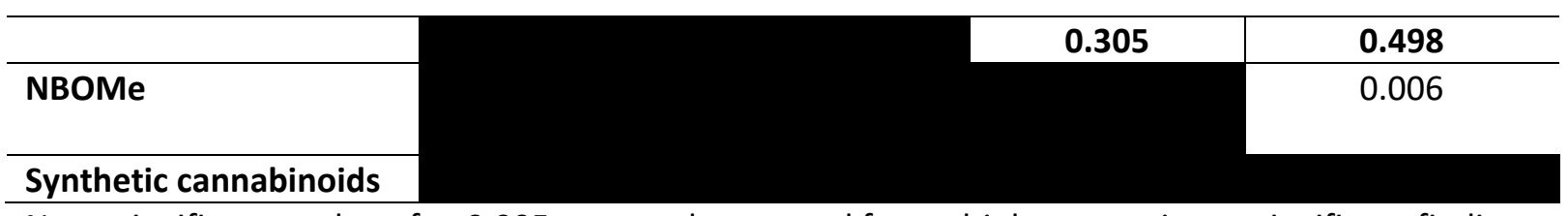

Note: significance value of $p \leq 0.005$ was used to control for multiple comparisons; significant findings bolded. When significant differences were found, Cramer's V is also reported. 


\section{References}

Australian Institute of Health \& Welfare. (2014). 2013 National Drug Strategy Household Survey: Detailed Findings. Retrieved from Canberra:

Barnard, M., Russell, C., McKeganey, N., \& Hamilton-Barclay, T. (2016). The highs and lows of NPS/“Legal High” use: Qualitative views from a UK online survey. Drugs: Education, Prevention and Policy, 1-7. doi:10.1080/09687637.2016.1201046

Barratt, M. J., Allen, M., \& Lenton, S. (2014). "PMA Sounds Fun": Negotiating Drug Discourses Online. Substance Use \& Misuse, 49(8), 987-998. doi:10.3109/10826084.2013.852584

Barratt, M. J., Cakic, V., \& Lenton, S. (2013). Patterns of synthetic cannabinoid use in Australia. Drug and Alcohol Review, 32(2), 141-146. doi:10.1111/j.1465-3362.2012.00519.x

Bonar, E. E., Ashrafioun, L., \& Ilgen, M. A. (2014). Synthetic cannabinoid use among patients in residential substance use disorder treatment: Prevalence, motives, and correlates. Drug and Alcohol Dependence, 143, 268-271. doi:http://dx.doi.org/10.1016/i.drugalcdep.2014.07.009

Bright, S. J., Bishop, B., Kane, R., Marsh, A., \& Barratt, M. J. (2013). Kronic hysteria: Exploring the intersection between Australian synthetic cannabis legislation, the media, and drug-related harm. International Journal of Drug Policy, 24(3), 231-237. doi:http://dx.doi.org/10.1016/i.drugpo.2012.12.002

Brunt, T. M., Poortman, A., Niesink, R. J., \& van den Brink, W. (2011). Instability of the ecstasy market and a new kid on the block: mephedrone. Journal of Psychopharmacology, 25(11), 1543-1547. doi:10.1177/0269881110378370

Cakic, V., Potkonyak, J., \& Marshall, A. (2010). Dimethyltryptamine (DMT): Subjective effects and patterns of use among Australian recreational users. Drug and Alcohol Dependence, 111(1-2), 30-37. doi:http://dx.doi.org/10.1016/j.drugalcdep.2010.03.015

Darke, S. (1998). Self-report among injecting drug users: A review. Drug \& Alcohol Dependence, 51(3), 253-263. doi:10.1016/S0376-8716(98)00028-3

Erowid. (2013). Spotlight on NBOMes: Potent Psychedelic Issues. Retrieved from https://www.erowid.org/chemicals/nbome/nbome article1.shtml

Erowid. (2015). DMT effects. Retrieved from https://www.erowid.org/chemicals/dmt/dmt effects.shtml

Erowid. (2016a). LSD effects. Retrieved from https://www.erowid.org/chemicals/lsd/Isd effects.shtml

Erowid. (2016b). Psilocybin Mushrooms effects. Retrieved from https://www.erowid.org/plants/mushrooms/mushrooms effects.shtml

European Monitoring Centre for Drugs and Drug Addiction. (2016a). EU Drug Markets Report. In-depth Analysis. Retrieved from Luxembourg:

European Monitoring Centre for Drugs and Drug Addiction. (2016b). Health responses to new psychoactive substances. Retrieved from Luxembourg:

Gunderson, E. W., Haughey, H. M., Ait-Daoud, N., Joshi, A. S., \& Hart, C. L. (2014). A Survey of Synthetic Cannabinoid Consumption by Current Cannabis Users. Substance Abuse, 35(2), 184-189. doi:10.1080/08897077.2013.846288

IBM Corporation. (2013). IBM SPSS Statistics for Windows, Version 22.0. Armonk, NY: IBM Corporation.

Johnston, L. D., O'Malley, P. M., Bachman, J. G., Schulenberg, J. E., \& Miech, R. A. (2015). Monitoring the Future national survey results on drug use, 1975-2014: Volume 2, College students and adults ages 19-55. Retrieved from The University of Michigan:

Lader, D. (2015). Drug Misuse: Findings from the 2014/15 Crime Survey for England and Wales. Retrieved from London:

Lawn, W., Barratt, M., Williams, M., Horne, A., \& Winstock, A. (2014). The NBOMe hallucinogenic drug series: Patterns of use, characteristics of users and self-reported effects in a large international sample. Journal of Psychopharmacology, 28(8), 780-788. doi:10.1177/0269881114523866

Matthews, A., Sutherland, R., Peacock, A., Van Buskirk, J., Whittaker, E., Burns, L., \& Bruno, R. (In Press). I like the old stuff better than the new stuff? Subjective experiences of new psychoactive substances. International Journal of Drug Policy. doi:10.1016/j.drugpo.2016.11.004

Measham, F., \& Newcombe, R. (2016). What's so new about new psychoactive substances? Definitions, prevalence, motivations, user groups and a proposed new taxonomy. In K. B. Thom \& G. Hunt (Eds.), The SAGE Handbook of Drug \& Alcohol Studies (Vol. 1). London: Sage.

Moore, K., Dargan, P. I., Wood, D. M., \& Measham, F. (2013). Do Novel Psychoactive Substances Displace Established Club Drugs, Supplement Them or Act as Drugs of Initiation? The relationship between Mephedrone, Ecstasy and Cocaine. European Addiction Research, 19(5), 276-282.

Orsolini, L., Papanti, G. D., Francesconi, G., \& Schifano, F. (2015). Mind Navigators of Chemicals' Experimenters? A WebBased Description of E-Psychonauts. Cyberpsychology, Behavior, and Social Networking, 18(5), 296-300. doi:10.1089/cyber.2014.0486

Palamar, J. J. (2015). "Bath salt" use among a nationally representative sample of high school seniors in the United States. The American Journal on Addictions, 24(6), 488-491. doi:10.1111/ajad.12254

Palamar, J. J., \& Acosta, P. (2015). Synthetic cannabinoid use in a nationally representative sample of US high school seniors. Drug and Alcohol Dependence, 149, 194-202. doi:http://dx.doi.org/10.1016/j.drugalcdep.2015.01.044

Reuter, P., \& Pardo, B. (2017). Can new psychoactive substances be regulated effectively? An assessment of the British Psychoactive Substances Bill. Addiction, 112(1), 25-31. doi:10.1111/add.13439 
Sindicich, N., \& Burns, L. (2015). Australian Trends in Ecstasy and Related Drug Markets 2014. Findings from the Ecstasy and Related Drugs Reporting System (EDRS). Retrieved from Sydney:

Soussan, C., \& Kjellgren, A. (2015). "Chasing the high" - Experiences of ethylphenidate as described on international internet forums. Substance Abuse: Research and Treatment, 9, 9-16. doi:10.4137/SART.S22495

Soussan, C., \& Kjellgren, A. (2016). The users of Novel Psychoactive Substances: Online survey about their characteristics, attitudes and motivations. International Journal of Drug Policy, 32, 77-84. doi:10.1016/j.drugpo.2016.03.007

Sutherland, R., Peacock, A., Whittaker, E., Roxburgh, A., Lenton, S., Matthews, A., . . Bruno, R. (2016). New psychoactive substance use among regular psychostimulant users in Australia, 2010-2015. Drug and Alcohol Dependence, 161, 110-118. doi:http://dx.doi.org/10.1016/i.drugalcdep.2016.01.024

United Nations Office on Drugs and Crime. (2014). Global SMART Update. Special segment: The changing nature of "ecstasy". Retrieved from Vienna: https://www.unodc.org/documents/scientific/Global SMART Update 11 web.pdf

van Amsterdam, J. G. C., Nabben, T., Keiman, D., Haanschoten, G., \& Korf, D. (2015). Exploring the Attractiveness of New Psychoactive Substances (NPS) among Experienced Drug Users. Journal of Psychoactive Drugs, 47(3), 177-181. doi:10.1080/02791072.2015.1048840

Van Buskirk, J., Roxburgh, A., Bruno, R., \& Burns, L. (2015). Retrieved from Sydney:

Vogels, N., Brunt, T. M., Rigter, S., Van Dijk, P., Vervaeke, H., \& Niesink, R. J. M. (2009). Content of ecstasy in the Netherlands: 1993-2008. Addiction, 104(12), 2057-2066. doi:10.1111/j.1360-0443.2009.02707.x

Wilkins, C., \& Sweetsur, P. (2013). The impact of the prohibition of benzylpiperazine (BZP) 'legal highs' on the prevalence of BZP, new legal highs and other drug use in New Zealand. Drug and Alcohol Dependence, 127(1-3), 72-80. doi:http://dx.doi.org/10.1016/j.drugalcdep.2012.06.014

Winstock, A. R., \& Barratt, M. J. (2013). Synthetic cannabis: A comparison of patterns of use and effect profile with natural cannabis in a large global sample. Drug and Alcohol Dependence, 131(1-2), 106-111. doi:http://dx.doi.org/10.1016/i.drugalcdep.2012.12.011

Winstock, A. R., Kaar, S., \& Borschmann, R. (2014). Dimethyltryptamine (DMT): Prevalence, user characteristics and abuse liability in a large global sample. Journal of Psychopharmacology, 28(1), 49-54. doi:10.1177/0269881113513852

Winstock, A. R., Lawn, W., Deluca, P., \& Borschmann, R. (2016). Methoxetamine: An early report on the motivations for use, effect profile and prevalence of use in a UK clubbing sample. Drug and Alcohol Review, 35(2), 212-217. doi:10.1111/dar.12259 